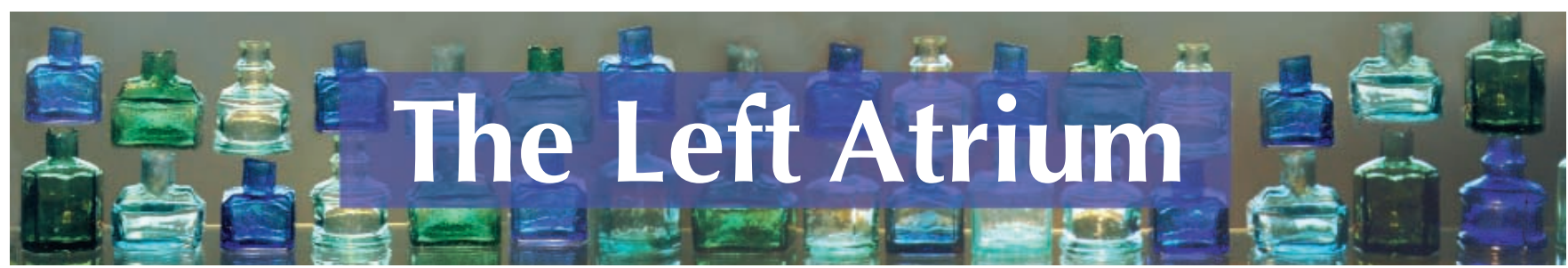

\section{No quick fix}

FIX: the story of an addicted city

A documentary film

Nettie Wild, director

Vancouver: Canada Wild Productions; 2002

Feature length: $93 \mathrm{~min}$; television version: $45 \mathrm{~min}$

66 0 you have any idea what you're talking about?" Ann Livingston, co-founder of the Vancouver Area Network of Drug Users (VANDU), puts that question to a reporter in the documentary Fix: The Story of An Addicted City.

The reporter, spiral notepad in hand, has just asked why injection drug users shouldn't just be put into treatment programs, the implication being that such a move would solve the problems of the city's Downtown Eastside.

Livingstone's response is not meanspirited, but instead conveys mild disbelief that anyone would think that there are easy answers. Treatment isn't particularly effective for heroine users: only 3 out of 100 who've gone through treatment are abstinent after one year, she explains.

FIX is a compelling documentary about the problems of Vancouver's Downtown Eastside, the activist group VANDU and its fight for safe injection sites, the politicization of (now former) mayor Philip Owen, and the charismatic VANDU organizors Livingstone and Dean Wilson, a heroin addict.

This downtown section of Vancouver entered an international spotlight in 1996, when it was declared to have the highest rate of HIV infection in the developed world, a situation brought about by shared needle use and exacerbated by the availability of injectable cocaine (which addicts inject 10 to 15 times a day, compared to 2 or 3 times a day for heroin).

But HIV/AIDS is mentioned only in passing in this film, which is about "keeping people alive." Safe injection sites, Livingston goes on to tell the re- porter, will at least give drug addicts the message that people care enough to keep them alive. "You can't get off drugs if you're not alive," she observes.

The feature-length documentary by director Nettie Wild, whose previous credits include an award-winning documentary about the peasant uprising in Chiapas, Mexico, was filmed over a period of almost two years, starting in 2000. It is a major accomplishment in that it manages to be a work of advocacy that is, at the same time, fairly evenhanded in its treatment of the range of players, including the police and the local business community. No one is demonized by the filmmaker, although it is startling to hear one local opponent of safe injection sites tell the camera, "We have compassion and goodwill for those drug addict monsters."

At one level, the documentary chronicles the struggle to establish safe injection sites, a move that VANDU and others hope will cut down on the obscenely high death rate among Vancouver junkies. This struggle represents a disavowal of an American-style "war on drugs" approach to the problem and move toward a more European-style "harm reduction" model. In the late 1980s it became clear that what was happening in downtown Vancouver was a health issue, not just a law-andorder issue, Owen explains.

A major reason for the high death rate - Wilson notes that in one year there were 400 overdose deaths in Vancouver - is unsafe injection. Interspersed throughout the documentary are gritty street scenes of junkies in alleyways injecting themselves and their fellow addicts with heroine and cocaine.
The scenes filmed at night have a nightmarish quality, while the daytime street scenes are a waking nightmare. Mayor Owen tells the camera that the city spends half a million dollars a year just on ambulance service reponses to drug-related incidents in downtown Vancouver.

But the documentary is also a profile of Livingston, who is a remarkable advocate. The very idea that junkies could be organized - she co-founded VANDU in 1998 - is astonishing. At the beginning of the AIDS epidemic, when gay men and heroin users were the primary victims of the disease, the truism was that gay men could (and did) organize around the epidemic because they were members of a politicized, connected community, while no one could expect junkies to get it together to form an organized lobby group. VANDU puts the lie to that. FIX includes a few scenes of raucous meetings and also captures a poignant moment when a roomful of men and women stand and silently remember two of their recently deceased fellow addicts.

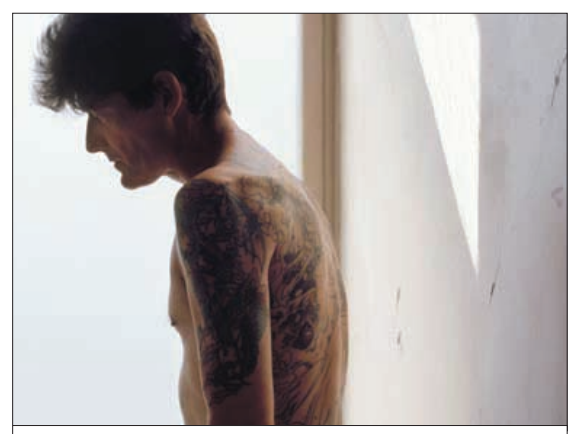

VANDU president Dean Wilson in a scene from $F I X$

Livingston, a single parent with three children, is motivated by her faith and her belief in Christ's message that you should reach out to people who have nothing and "stand in the most uncomfortable place." "I hate this," she says at one point. "Any time someone can convince me there is something 
more pressing and needs me more, then I'll go do it." She is neither sanctimonious ( she swears regularly) nor strident, and she has a wry sense of humour. A local policeman, who is no fan of the idea of safe injection sites, describes her as "a rebel with a cause" and a good advocate who takes not a balanced but a passionate approach.

Finally, the documentary is also the story of the relationship between Livingston and Wilson, who are clearly fascinated by each other. This focus intensifies as the documentary proceeds. FIX opens with Wilson and shows him shooting up. Throughout the docu- mentary he struggles with his addiction, trying to wean himself off heroin and, later, methadone, going to detox for eight days and relapsing to heroin use. ("It is," as one unidentified woman states in the film, "a chronic relapsing illness. That is what we have to recognize.") Wilson talks about how often he has let Livingston down; she points out his evasions and lies and acknowledges his drive to manipulate. Immediately after seeing the documentary, I didn't like the steady shift away from the political story in favour of this personal one. But later, I came to think the tension, danger and mystery inherent in the personal relationship are of a piece with this documentary's other themes of struggle. There are no easy answers to the problems of Vancouver's Downtown Eastside. But in this film, those more affected are allowed to voice their first priority: staying alive.

\section{Ann Silversides \\ Journalist \\ Toronto, Ont.}

Ann Silversides is the author of AIDS Activist: Michael Lynch and the Politics of Community. Toronto: Between the Lines; 2003.

\section{Lifeworks}

\section{Regeneration}

$\mathrm{T}$ ravelling through rural upstate New York in 1986 and feeling like a misplaced tourist, photographer Andrea Modica came across a farmhouse owned by a family with 14 children. Struck by this large number, she approached and asked if she could take some photographs. She was particularly captivated by an eight-year-old girl named Barbara. Their first meeting sparked a 15-year relationship that ended only with Barbara's death in 2001 from complications of juvenile diabetes. These photographs form the basis of Modica's exhibition, Barbara, which was on view at the Edwynn Houk Gallery in New York City from March 4 to April $17,2004$.

The 41 works in the show, displayed chronologically, reflected only a small sample of the many photographs produced during this long-term collaboration between artist and subject. Modica first documented Barbara as a young girl posed within her rundown environment, and followed her to her final illness, in which she appears as a shadowy presence immobilized in a darkened room. The closelycropped images are printed as 8 " $\times 10$ " platinum contact prints. The breadth of detail and tone inherent in this process, as well as the small size of the prints, reinforce the powerful intimacy of Modica's arresting images.

In Modica's first, pivotal image of Barbara in 1986, the young girl sits with her head turned to one side, a single hand held to her chest, projecting a maturity beyond her years. In her gaze and posture there is the sense of someone who intuitively recognizes the burden of a world that she has not yet experienced. During their periodic photo-

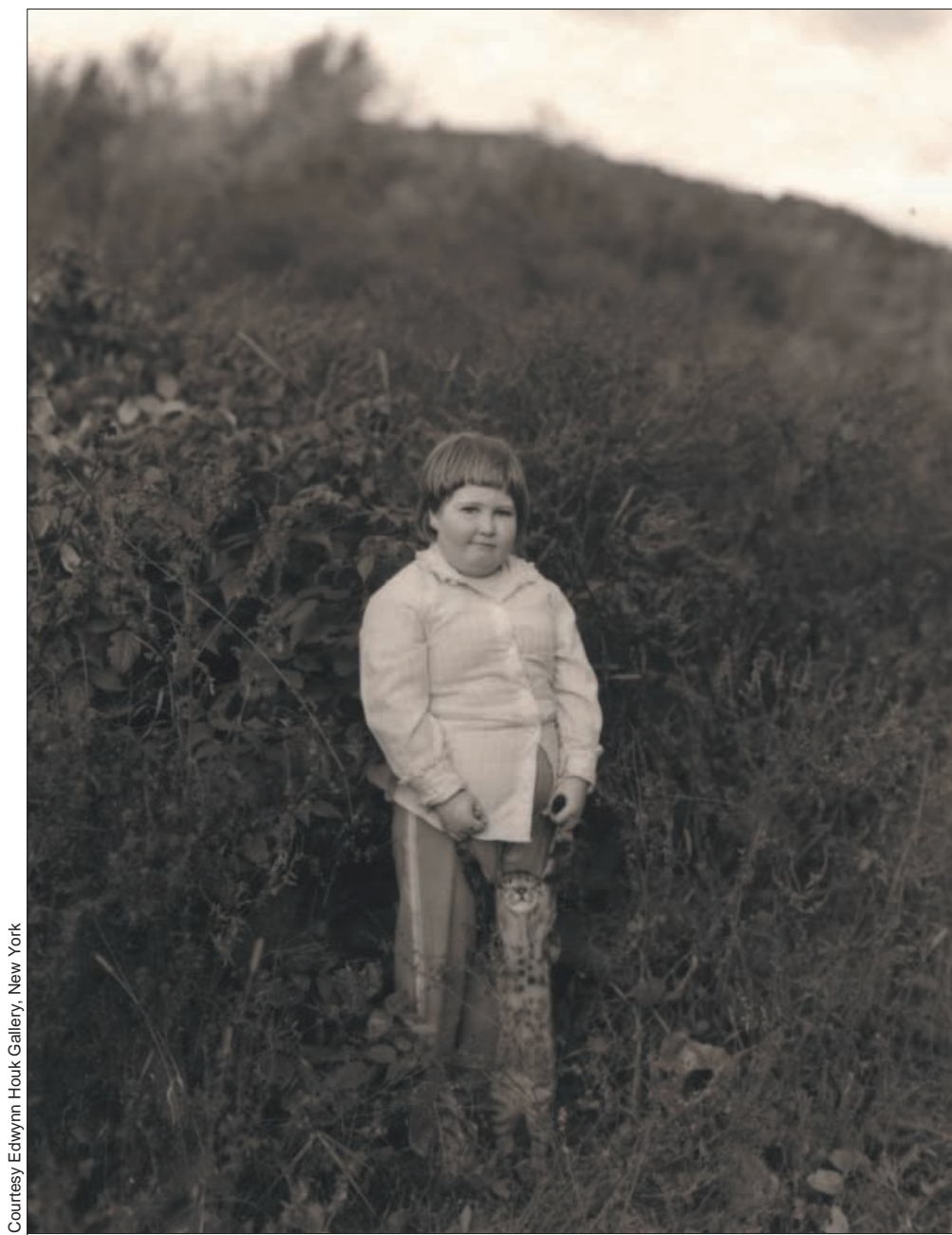

Andrea Modica. Treadwell, NY, 1987. Platinum contact print. 